\title{
COMMUNICATIONS
}

\section{NEURORETINOPATHY FOLLOWING HAEMORRHAGE* WITH A DISCUSSION ON THE NATURE OF CYTOID BODIES \\ BY}

\author{
N. ASHTON, M. A. PEARS, AND G. W. PICKERING \\ Institute of Ophthalmology, London, and Radcliffe Infirmary, Oxford
}

HAEMORRHAGE from any site, and the commonest is the gut, may provoke two profound disturbances of the retina. The best recognized is blindness which begins suddenly, and is associated with subsequent swelling of the disc and often with optic atrophy. A less known but common sequel is a neuroretinopathy, first described by Ulrich (1887) and closely resembling ophthalmoscopically the neuroretinopathy of the malignant phase of hypertension. One case of the first type and seven of the second type were described as sequels of gastro-intestinal haemorrhage by Pears and Pickering (1960). Case 7 of their series died, and we here briefly describe the clinical history and the details of the ocular changes.

\section{Case Report}

Clinical History.-The patient was a 75-year-old retired jeweller, who had had no symptoms suggestive of peptic ulcer in his life. For some 12 months before admission to hospital, he had noticed that, on walking upstairs or digging in his garden, he would experience a pain situated retro-sternally without radiation and accompanied by breathlessness. This pain was relieved by rest and bore no relation to food or to posture. On the morning of December 5, 1957, he woke up feeling a little nauseated and did not want his breakfast. He passed a large black stool, after which he felt dizzy and faint. At this time his relatives noticed that he was pale and sweating. He went back to bed and after some hours felt better and had a normal lunch, but later in the afternoon vomited about 2 to 3 pints of altered blood, and was on that account admitted to hospital. In the ambulance on the way to hospital he vomited several ounces more of altered blood and did this again in the Casualty Department on arrival. He had taken no drugs other than occasional aspirin tablets to help him to sleep, and he had had none of these for 3 days before his illness.

Examination.-He was pale, with cold extremities and was vomiting a few ounces of blood from time to time.

Cardiovascular System: Pulse 90/min., regular rhythm. Blood pressure 120/65. Apex beat $5^{\prime \prime}$ in the fifth left interspace, with a normal impulse. No signs of failure.

Respiratory System: No abnormal physical signs.

Central Nervous System: No abnormal physical signs.

Gastro-intestinal System: No jaundice was present. There were no spider naevi. The palms of the hands were normal. No forearm pulsation was present; no clubbing of the fingers; no visible venous collaterals on the anterior abdominal wall. The liver and spleen were impalpable. There were no masses, rigidity, tenderness, or guarding. 
Rectal examination showed the presence of a malaena stool.

Eyes: The fundi on admission were both quite normal. The discs were clearly defined, the vessels showed no irregularities of calibre, and there were no haemorrhages or exudates.

Haemoglobin: On admission 85 per cent. On the next day, in spite of receiving 2 pints of blood, it was 50 per cent. On no occasion subsequently was the haemoglobin known to fall below 50 per cent.

Treatment.-The patient was admitted to the ward and blood transfusion was started at once. During the course of the next 9 days he received a total of 16 pints of blood. By December 13, 1957, the haemoglobin had reached a level of 70 per cent. During the first $\mathbf{7 2}$ hours after admission, there were four short periods, none longer than $\mathbf{3 0}$ minutes, during which the systolic blood pressure dropped to $100 \mathrm{~mm}$. $\mathrm{Hg}$ or below, and the patient became sweaty, pale, and cold. On the second of these occasions he lost consciousness for one minute. After December 8, 1957, the blood pressure remained within normal limits. From December 14, 1957, there were no further signs of continuing haemorrhage and he was making a good recovery from his illness.

Progress.-On December 28, 1957, he became breathless and developed abnormal signs in the lungs, and 3 days later he died suddenly.

Autopsy.-On January 1, 1958, a chronic peptic ulcer was found on the lesser curvature of the stomach just proximal to the pylorus. There was in addition a massive pulmonary embolus astride the main branches of the pulmonary artery and evidence of recent infarction of the lower lobe of the right lung. Ante mortem thrombus was present in the left femoral vein.

Retinal Lesions.-The fundi had been inspected twice daily, every day, and until the morning of December 10, 1957, they were both completely normal. On that morning the first retinal lesion was seen in the right fundus. This consisted of an ill-defined exudate lying partly across the right superior temporal artery about one disc diameter along its course, measuring about a half-disc diameter in its long axis. On December 11, 1957, a second lesion was seen in the right fundus; this consisted of a small oval exudate about one-quarter of a disc diameter in its long axis, lying just lateral to the superior nasal artery as it left the disc border. On this day, too, two lesions were seen in the left fundus. Of these, one was an exudate lying across the inferior nasal artery about a halfdisc diameter in its long axis and about a quarter-disc diameter out along the course of the vessel. The second was a small oval exudate about a half-disc diameter in its long axis lying between the inferior temporal vessels about one disc diameter out along their course. On December 14, 1957, an additional lesion was seen in the left fundus. This was a small oval exudate about one-fifth of a disc diameter in length, lying just below the superior nasal artery about one-and-a-half disc diameters out along its course. On December 15, 1957, three further lesions were seen: two of these were in the right fundus and consisted of two small linear haemorrhages lying just above the upper edge of the disc and just lateral to the exudate already described near the superior nasal artery as it crossed the border of the optic disc; the third was in the left fundus and lay lateral to and parallel with the inferior temporal artery about a half-disc diameter out along its course. Of the lesions, all the exudates appeared to attain their maximum size within 12 hours and thereafter remained unchanged until about December 19, 1957, when the first, second, third, fourth, and eighth lesions described above began to grow fainter. By December 28, 1957, the second lesion was practically invisible, and the other lesions were all appreciably fainter but still present. The two haemorrhages differed slightly in their development from the exudates. They were initially very small and of unequal size, but during the first 72 hours after their appearance they became of equal size, and increased to twice the initial size of the originally larger lesion. They were present unchanged on the day of death. 


\section{Pathological Findings}

The left eye was received in the laboratory 3 days after death and, in order to observe the fundus changes seen in life, the globe was opened transversely through the ora serrata. The anterior segment showed no abnormality. In the fundus there were two superficial exudates situated two disc diameters beneath the disc on the inferior temporal vessels in closer relation to the artery. There was also a smaller exudate between the inferior nasal vessels one-half disc diameter from the disc and another of similar size on the superior nasal artery at one disc diameter from the disc. A minute haemorrhage was present on the temporal side of the macula and there was considerable oedema of the whole of the posterior polar region of the retina. The retinal vessels showed post mortem collapse. A fundus painting of these post mortem findings is shown in Fig. 1.

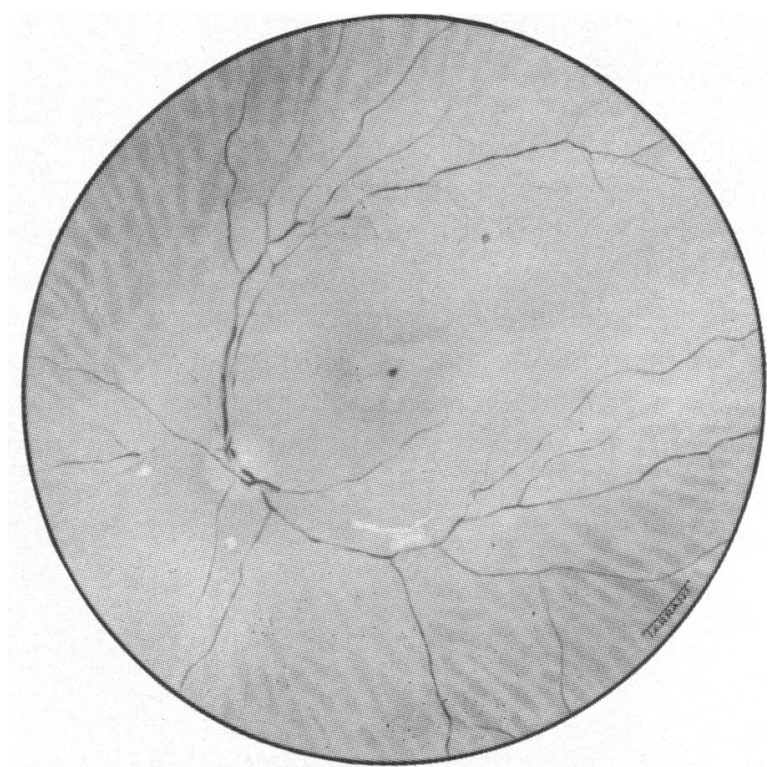

FIG. 1.-Fundus painting of post mortem eye, showing marked retinal oedema, cotton-wool exudates, and an isolated haemorrhage. The vessels show post mortem collapse.

The retina was then removed in toto and stained for fat with oil red $\mathrm{O}$. All the exudates stained positively and appeared as red granular patches against the faint pink of the normal retina (Figs 2 and 3, overleaf). The specimen was then stained by the periodic acid-Schiff method (PAS), but unfortunately only the main vessels gave a positive reaction, so that the condition of the smaller vessels and capillaries in the region of the exudates could not be discerned. The superficial exudates continued to show their fat-staining, but no positive-PAS material was present. 


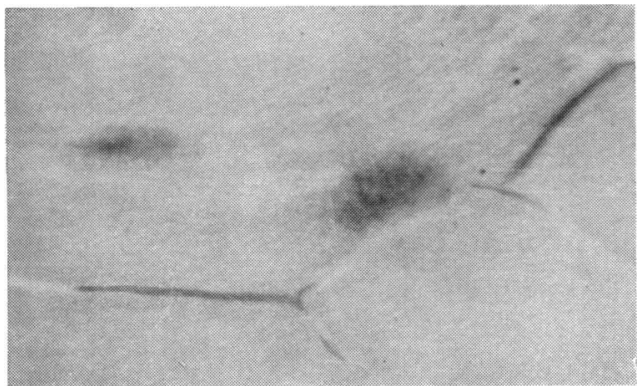

FIG. 2.-Flat retina stained with oil red $O$. Fat is present within the cotton-wool exudates.

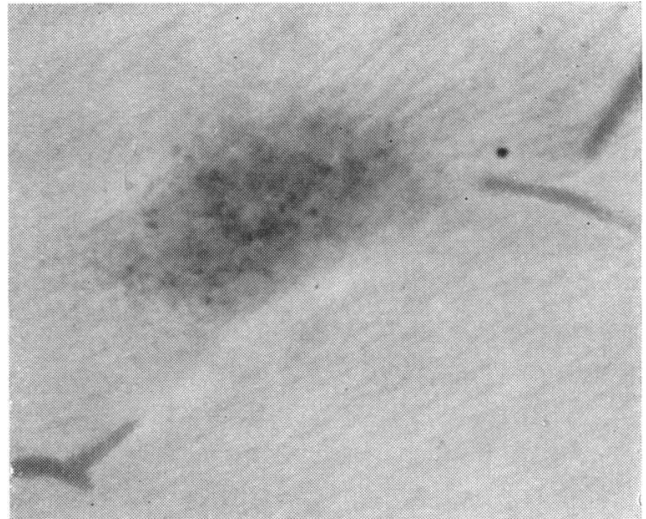

Fig. 3.-High-power view of Fig. 2, showing fat globules within the exudate.

A disc of retina containing the larger inferior exudates was now removed and longitudinal and transverse paraffin sections were cut and stained with haematoxylin and eosin, PAS with haematoxylin, and Weil's myelin sheath stain. All these sections showed an extreme degree of oedema, particularly in the stratum opticum, where numerous isolated or conglomerate cytoid bodies could be seen lying in close relation to a minute arteriole; a few of these structures lay immediately beneath the internal limiting membrane. They consisted of eosinophilic finely granular material trapped in cystic spaces between nerve fibres or their axon membranes which gave the appearance of a "cell membrane"; most of them but not all contained a central or eccentric, round or oval, pseudo-nucleus, which was either more intensely eosinophilic than the "cytoplasm" or frankly basophilic (Figs 4 and 5).

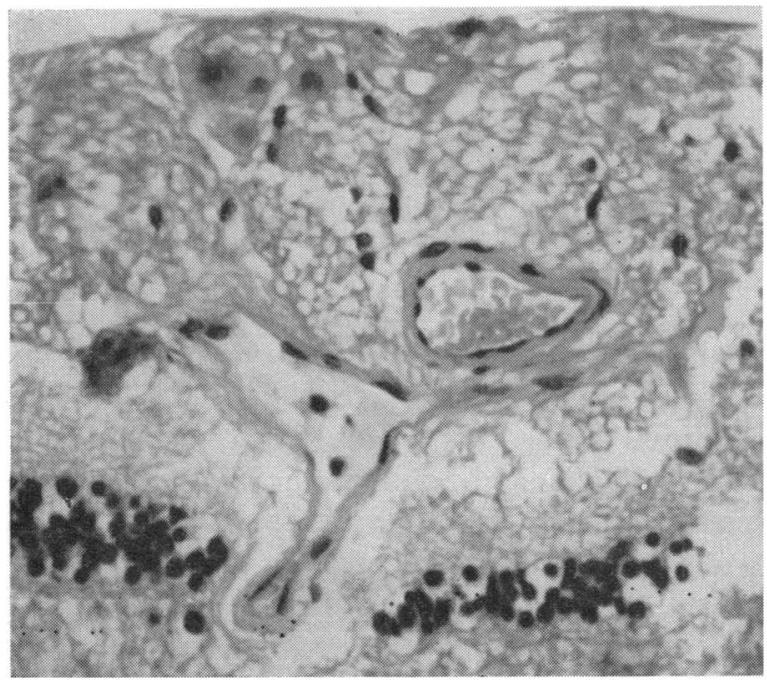

FIG. 4.-Transverse section through region of cotton-wool exudate (inferior temporal region). Note extreme oedema, particularly in the stratum opticum, and a group of cytoid bodies beneath the internal limiting membrane. The artery and vein show no abnormality. Haematoxylin and eosin. $\times 330$. 
Fig. 5.- Longitudinal section through a cotton-wool exudate, showing numerous cytoid bodies, which appear to consist of eosinophilic material entrapped between separated nerve fibres. Several central or eccentric basophilic pseudo-nuclei may be seen. Haematoxylin and eosin. $\times 330$.

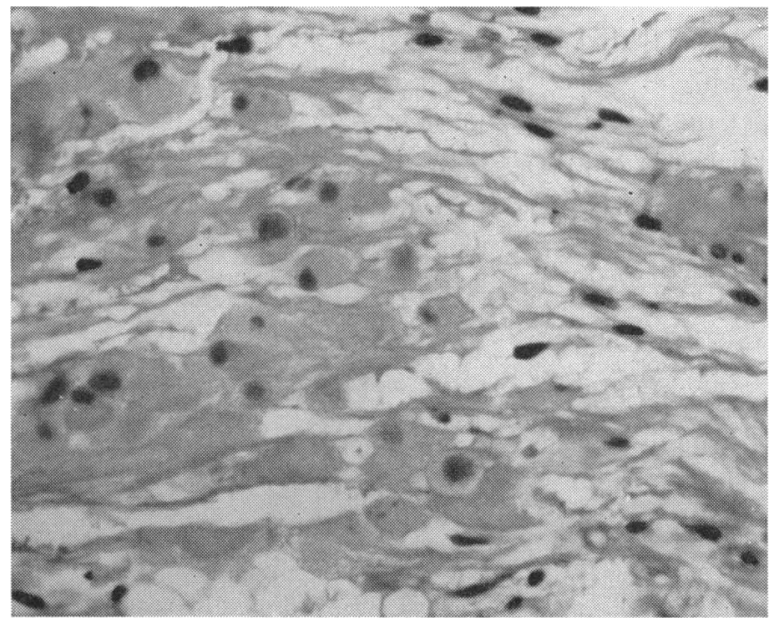

These areas were PAS-positive (Fig. 6) and stained intensely with Weil's myelin sheath stain (Fig. 7). Definite varicose nerve fibres could not be identified in either transverse or longitudinal sections.

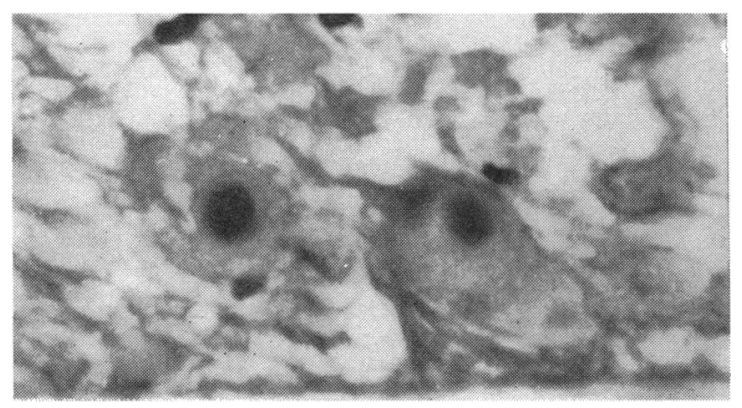

Fig. 6.-High-power view of cytoid bodies, showing positive PAS staining of the pseudo-nuclei. PAS stain. $\times 700$.

Fig. 7.-High-power view of cytoid bodies, showing intensely staining pseudo-nuclei, granular "cytoplasm", and an investing "cell membrane" derived from nerve fibres. Weil's myelin sheath stain. $\times 700$.




No abnormality could be detected in the small vessels in these oedematous areas, except in a few sections where plasma seemed to be streaming from a break in the wall of a minute arteriole (Fig. 8) to form a lake between the glial fibres. Since no new exudate had been seen for the previous 13 days this would appear to be either an old coagulated exudate or a recent lesion due to the asphyxia from which the patient died. There was no evidence of arteriolosclerosis or arteriolonecrosis or any other organic change in the vessels throughout all the sections.

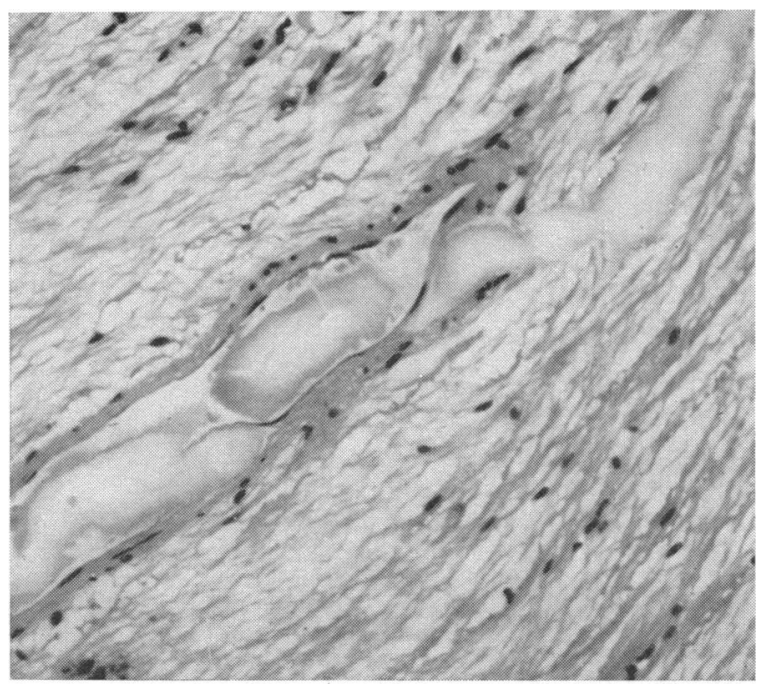

Fig. 8.-Arteriole adjacent to the focus of cytoid bodies, shows exudate streaming from a small break in its wall. No other abnormality was found in the vessels. Haematoxylin and eosin. $\times 210$.

The anterior segment of the eye and the remaining portion of the posterior segment were then sectioned in celloidin. An incidental finding was a minute melanoma of the choroid in the region of the ora serrata; the growth was spindle-celled and heavily pigmented and had a high reticulin content. The optic nerve showed a mild degree of oedema, but there was no evidence of any degenerative change. No abnormal vessels were found.

\section{Discussion}

The ophthalmoscopic appearances of linear haemorrhages and cottonwool exudates in this case were exactly similar to those frequently described in post-haemorrhagic states, the exudates being identical with those illustrated by Pick (1901) in two cases of anaemia from carcinoma of the stomach, and by Pines (1931) in a case of blood loss through miscarriage.

The pathological findings can be compared less readily, for only a few studies of this kind have previously been made, and curiously none has been reported in recent years. The earlier workers have described the pathology of cases where blood loss had been due to blood-letting (Esquirol, 1838), to haemorrhagic diathesis (Pagenstecher, 1905), to profuse menstruation (Ulrich, 1887), to post-partum haemorrhage (Rählmann, 1889), to severe 
gastric haemorrhage (Hirschberg, 1881; Zeigler, 1887; Seese, 1914; Goerlitz, 1920), and to carcinoma of the stomach (Nakaizumi, 1912). Holden (1899) and Uhthoff (1922) investigated microscopical changes in the retinae of dogs bled experimentally. The value of the reports on human material is limited by the long periods which had usually elapsed between the visual disturbances and the histological examination; in the present case, however, the retinopathy was known to be present on the day of death. Our findings of neuroretinal oedema, fatty degeneration, and cytoid bodies correspond with those reported by Goerlitz (1920): he was the first and only worker to have previously described cytoid bodies (which he referred to as varicose nerve fibres) in a case of haemorrhage, thus correlating the pathology with that found many years earlier in other severe anaemias (Uhthoff, 1880; Bettmann, 1882; Ulrich, 1887; Bondi, 1896; Litten, 1902; Pagenstecher, 1905) and with septic retinitis, in which condition varicose nerve fibres were originally described (Roth, 1872):

As in our case, cotton-wool exudates are found histologically to consist of conglomerate oedematous masses in the nerve fibre layer, containing as a principal component large eosinophilic cell-like structures many of which contain round or elongated pseudo-nuclei-the so-called "cytoid bodies". For many years they were unquestioningly accepted as varicose nerve fibres and are still so described in the French literature, but more recently other workers have maintained that they represent altered blood, or intra-retinal exudation, or ganglion cell degeneration, and controversy about their nature continues to the present day. Although Wolff (1951) in his text-book adhered to the old view, other recent writers speak of cytoid bodies as entrapped exudate within the supporting network of the nerve fibre layer (Kiewe and Hart, 1951), an opinion shared by Christensen (1958), who considers that the outer zone of the cytoid body is probably swollen precipitated ground substance, and the inner zone fibrin or fibrinoid material from the blood stream. In our case the appearances conform with this description. Friedenwald, Wilder, Maumenee, Sanders, Keyes, Hogan, Owens, and Owens (1952) believed cytoid bodies to be derived from the glial cells of the nerve fibre layer, while the most recent writers (Russell and Rubinstein, 1959) speak of cytoid bodies as synonymous with "Rosenthal fibres"-a peculiar type of glial degeneration seen in a variety of tumours of the nervous system (Grcevic and Yates, 1957). However, the exact nature of cytoid bodies is not the concern of this report and the controversy will not here be further pursued.

We, like Goerlitz (1920), have shown that these retinal lesions may develop after blood loss, but cytoid bodies also occur in a large variety of unrelated diseases quite apart from primary or secondary anaemias. They have, for instance, been demonstrated histologically in septicaemia, in the neuroretinopathy of the malignant phase of hypertension (whether based on essential or renal hypertension), in systemic lupus erythematosus, in dermatomyositis, 
and in carcinomatosis, although in this latter case anaemia has not been excluded as a cause.

It is interesting that these "cotton-wool exudates" are confined to the retinal fibre layer at the posterior pole, are usually multiple though rarely exceeding ten in number, and are situated close to the main vessels, disposed in a radius not exceeding 4 to 5 papillary diameters; the paramacular or macular zones are spared (Paufique and Royer, 1957). The tendency today to use the name "cytoid body" as a clinical term synonymous with cottonwool exudate is, however, undesirable, for this is purely a histological component of the lesion. At the present time "cotton-wool" or "fluffy" exudate are the only English terms available to describe this important feature of the ophthalmoscopic picture under consideration.

It is reasonable to assume that they represent a direct or indirect reaction of nerve fibres to vascular injury, but the exact nature of this injury is disputed; embolus, thrombus (Kümmell, 1932), and spasm (Friedenwald and others, 1952) have all been suggested, but whatever the initial cause the underlying process is most probably one of ischaemia and transudation.

The complete absence in our case of any structural abnormality in the intra-ocular vessels (apart from a minute break), including those retinal vessels immediately adjacent to the cotton-wool exudates, is of particular interest, as it would imply that functional rather than organic changes are involved in the genesis of neuroretinopathy after haemorrhage. Even in malignant hypertension it is still doubtful to what extent structural changes in the smaller vessels are responsible for the retinopathy. Although fatty and sclerotic degeneration has been demonstrated in vessels adjacent to cotton-wool exudates (Müller, 1858; Verwey, 1927; Friedenwald, 1932, 1935), these may well be secondary to ischaemic anoxia in this area from some other cause. It will be recalled that Volhard $(1921,1929)$ believed this anoxia to be due to spasm of the arterioles which was not only sufficient to injure the tissue supplied by the arteriole, but, in time, was also sufficient to injure the arteriolar and capillary endothelium. This view has now received support from the work of Abt and Brückner (1950) and of Byrom (1954), who have demonstrated focal and widespread constriction in the retinal, cerebral, and other vessels of rats with severe experimental hypertension. This appears to be a direct local response of the vessel wall to the physical strain of excessive intra-arterial tension, and, according to its degree of severity, can lead to a transient disturbance of function, increased capillary permeability with attendant focal oedema, and local necrosis of the arterial wall and the tissue supplied.

If the pathogenesis of the exudative lesions of the retinopathies of hypertension and haemorrhage are so closely related as their appearances would suggest, then the pathological basis could be focal ischaemia produced by constriction of the retinal arterioles or pre-capillary arterioles and by anaemia. 
To the ophthalmologist the fundus findings of neuroretinal oedema with haemorrhages and cotton-wool exudates, as seen in our case, is a familiar picture occurring in a whole range of differing disease states, as in other anaemias, in cachexia ("rétinite des cachectiques": Pick, 1901), in septic conditions ("rétinite septique": Roth, 1872), in the collagen diseases, in polyarteritis nodosa, in subacute bacterial endocarditis, and in hepatic disease (Streiff and Bischler, 1943; Buovolo, 1950; Bonamour, Bonnet, and Buovolo, 1950). However, the most familiar example is the neuroretinopathy of the malignant phase of hypertension, which has variously been termed albuminuric retinitis, angiospastic retinitis, renal retinitis, and Grade IV retinopathy. It has been suggested that a more general name should be applied to this whole group of retinopathies-such as "dysoric retinopathy" with cotton-wool exudates as "dysoric nodules" (Streiff and Bischler, 1943), and "retinal endothelitis" (Vouters, 1958)—but it would seem that our knowledge of the pathogenesis of these conditions is still too imperfect to adopt any generic term at the present time.

\section{Summary}

The pathological findings in a post mortem examination of the retina in a case of neuroretinopathy due to haemorrhage are described. The nature of the lesions is discussed in relation to other retinopathies which share the same features.

Our thanks are due to Messrs. G. Knight and A. McNeil for technical assistance and to Miss E. FitzGerald for secretarial help.

\section{REFERENCES}

ABT, K., and BrÜCKNER, R. (1950). Ophthalmologica (Basel), 119, 17.

Bettmann, B. (1882). Arch. Augenheilk., 11, 28.

Bonamour, G., Bonnet, J. L., and Buovolo, J. (1950). Bull. Soc. franç. Ophtal., 63, 126.

Bondi, M. (1896). Arch. Augenheilk., 33, Suppl. (Festschrift Dr. J. Schnabel), p. 85.

Buovolo, J. (1950). "La rétinopathie dysorique". Thèse, Lyon.

BYROM, F. B. (1954). Lancet, 2, 201.

CHRISTENSEN, L. (1958). Trans. Amer. ophthal. Soc., 56, 451.

EsQUIROL, E. (1838). "Des maladies mentales", vol. 1, p. 183. Baillière, Paris.

FrIEDENWALD, J. S. (1932). In "Contributions to the Medical Sciences in Honor of Dr. Emanuel Libman", vol. 2, p. 453. International Press, New York.

(1935). In "The Kidney in Health and Disease", ed. H. Berglund and G. Medes, p. 638. Lea and Febiger, Philadelphia.

Wilder, H. C., Maumenee, A. E., Sanders, T. E., Keyes, J. E. L., Hogan, M. J., and OWENS, W. C., and OWENS, E. U. (1952). "Ophthalmic Pathology. An Atlas and Textbook", p. 316. Saunders, Philadelphia.

Goerlitz, M. (1920). Klin. Mbl. Augenheilk., 64, 763.

GrCeVic, N., and Yates, P. O. (1957). J. Path. Bact., 73, 467.

HIRSCHBERG, J. (1881). Ber. ophthal. Ges. Heidelberg, 13 Versammlung, p. 69.

Holden, W. A. (1899). Arch. Ophthal. (N.Y.), 28, 125.

KIEWE, P. L., and HART, F. DUdley (1951). Trans. ophthal Soc. U.K., 71, 309.

KüMMELl, R. (1932). In "Kurzes Handbuch der Ophthalmologie", ed. F. Schieck and A. Brückner, vol. 7, p. 62 . Springer, Berlin.

LITTEN, M. (1902). Dtsch. med. Wschr., 28, 37.

MüLLER, H. (1858). Verhandlungen phys. med. Ges. Würzburg.

NaKaizumi, Y. (1912). Klin. Mbl. Augenheilk., 50, n.s. 13, 290. 
Pagenstecher, A. H. (1905). Arch. Augenheilk., 52, 237.

PAUFiQUe, L., and RoYer, J. (1957). J. Méd. Lyon, p. 583.

Pears, M. A., and Pickering, G. W. (1960). Quart. J. Med., 29, 153.

Pick, L. (1901). Klin. Mbl. Augenheilk., 39 (Part I), 177.

PINES, N. (1931). Brit. J. Ophthal., 15, 75.

RÄHLMANN (1889). Fortschr. Med., 7, 928.

RoTH, M. (1872). Virchows Arch. path. Anat., 55, 197.

Russell, D. S., and Rubinstein, L. J. (1959). "The Pathology of Tumours of the Nervous System ". Arnold, London.

SEeSE, M. W. A. (1914). "Sehstörungen nach Blutverlust". Diss., Jena.

STREIFF, E. B., and BischleR, V. (1943). Ophthalmologica (Basel), 105, 229.

Uнтноғ, W. (1880). Klin. Mbl. Augenheilk., 18, 513. (1922). Ber. ophthal. Ges., 43, 204.

UlRich, R. (1887). v. Graefes Arch. Ophthal., 33 (Part 2), p. 1.

VerWEY, B. C. DE LA F. (1927). Klin. Mbl. Augenheilk., 79, 148.

VOLHARD, F. (1921). Zbl. ges. Ophthal., 5, 470. (1929). Ibid., 21, 129.

VOUTERS, J. (1958). Arch. Ophthal., 18, 262.

WolfF, E. (1951). "A Pathology of the Eye", 3rd ed. Lewis, London.

ZIEGLER, E. (1887). Beitr. path. Anat. Physiol., 2, 57. 